CÂMARA, L.R.A. et al. Zeolita na dieta de bovinos de corte. PUBVET, Londrina, V. 5, N. 26, Ed. 173, Art. 1168, 2011.

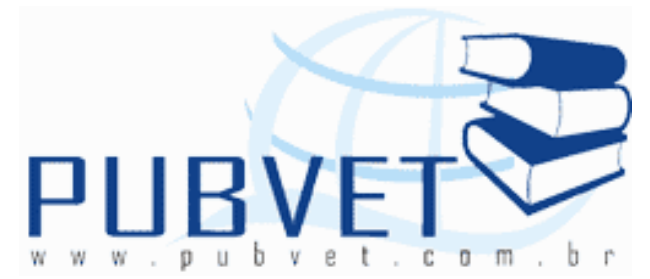

PUBVET, Publicações em Medicina Veterinária e Zootecnia.

\title{
Zeolita na dieta de bovinos de corte
}

Larissa Rodrigues de Azevedo Câmara ${ }^{1}$, Sebastião de Campos Valadares
Filho $^{2}$, Ana Paula Cardoso Gomide ${ }^{1}$, Maria Ignez Leão², Bruno Andreatta

Scottá1, Camila Carneiro ${ }^{3}$

\section{Resumo}

A criação de bovinos de corte é uma prática em ascensão em diversas regiões do Brasil. Sendo a alimentação o principal fator de custo da propriedade, torna-se muito importante o estudo de meios que possam aumentar a capacidade de aproveitamento da dieta pelos animais, tornando mais viável a utilização de determinados nutrientes. Por esse motivo, nos últimos anos, tem havido considerável interesse na redução das perdas de compostos nitrogenados (N) pelos ruminantes. Dentre estes meios está a utilização de aditivos, sendo que alguns já estão consolidados (antibióticos, ionóforos, tamponantes) e outros ainda estão sendo avaliados (zeolita). A alta capacidade de troca catiônica e a marcada preferência pelo $\mathrm{NH}_{4}{ }^{+}, \mathrm{K}^{+}, \mathrm{Ca}{ }^{2+}, \mathrm{Na}^{+}$e $\mathrm{Mg}^{2+}$ 
CÂMARA, L.R.A. et al. Zeolita na dieta de bovinos de corte. PUBVET, Londrina, V. 5, N. 26, Ed. 173, Art. 1168, 2011.

fazem crer que a zeolita tem um alto potencial para ser usada como aditivo alimentar.

Palavras-chave: aditivo, nutrição, ruminantes, ureia, zeolita

\title{
Zeolite in the diet of beef cattle
}

\begin{abstract}
The establishment of beef cattle is a rise in circulation in various regions of Brazil. As eating is the main factor of cost of owner ship, it becomes very important to study ways to enhance the ability of dietary energy utilization by animals, makingit feasibleto use certain nutrients. For this reason, in recent years, there has been considerable interest in reducing losses of nitrogen $(\mathrm{N})$ by ruminants. Among these means is the use of additives, some of which areal ready consolidated (antibiotics, ionophores, buffers) and others are still being evaluated (zeolite). The high cation exchange capacity and the marked preference for do $\mathrm{NH}_{4}{ }^{+}, \mathrm{K}^{+}, \mathrm{Ca}^{2+}, \mathrm{Na}^{+}$e $\mathrm{Mg}^{2+}$ believe that the zeolite has a high potential to be used as a food additive.
\end{abstract}

Keywords: additive, nutrition, ruminants, urea, zeolite

\section{Revisão de literatura}

A criação de bovinos de corte é uma prática em ascensão em diversas regiões do Brasil. Sendo a alimentação o principal fator de custo da propriedade, torna-se muito importante o estudo de meios que possam aumentar a capacidade de aproveitamento da dieta pelos animais, tornando mais viável a utilização de determinados nutrientes. Dentre estes meios está a utilização de aditivos, sendo que alguns já estão consolidados (antibióticos, ionóforos, tamponantes) e outros ainda estão sendo avaliados (zeolita).

A melhora da eficiência da fermentação ruminal, por meio do aumento da produção de ácido propiônico, da diminuição da metanogênese ou da diminuição da proteólise e deaminação de proteínas no rúmen, são buscas incessantes dos pesquisadores da área de nutrição de ruminantes (Bergen \& 
CÂMARA, L.R.A. et al. Zeolita na dieta de bovinos de corte. PUBVET, Londrina, V. 5, N. 26, Ed. 173, Art. 1168, 2011.

Bates, 1984). Considerando os altos custos da proteína da dieta, a economia da produção animal é altamente dependente da eficiência de sua utilização. Por esse motivo, nos últimos anos, tem havido considerável interesse na redução das perdas de compostos nitrogenados $(\mathrm{N})$ pelos ruminantes (Russel, 1992).

Durante muito tempo, procurou-se atingir esses objetivos por meio da manipulação da dieta, porém, nas últimas décadas um grande número de compostos químicos tem sido testado para os mesmos fins. Os aluminossilicatos são uma classe desses compostos que teve considerável sucesso como aditivo alimentar.

As zeolitas são minerais silicatos hidratados de alumínio e metais alcalinos e alcalinos terrosos normalmente encontrados em rochas sedimentares. Suas reservas estão localizadas em diversas regiões da terra, tanto assim que Instituições de Pesquisa de vários países vêm interessando em estudá-las (Mumpton \& Fishman, 1977). Existem diversas espécies de zeolitas, dentre estas a clinoptilolita, mordenita, amalcina, laumontila e erionita, que podem ser utilizadas para diferentes fins, seja na indústria agricultura, alimentação animal e aquicultura (Quarles, 1985). Castro et al. (1990) observaram que a alta capacidade de troca catiônica e a marcada preferência pelo $\mathrm{NH}_{4}{ }^{+}, \mathrm{K}^{+}, \mathrm{Ca}^{2+}, \mathrm{Na}^{+}$e $\mathrm{Mg}^{2+}$ fazem crer que a zeolita tem um alto potencial para ser usada como aditivo alimentar para diferentes espécies animais.

A uréia é um composto nitrogenado não-protéico, que quando ingerida, é hidrolisada em amônia, que dependendo do nível é tóxica para todos os animais vertebrados. Mas os ruminantes conseguem utilizar essa amônia, graças à simbiose com microrganismos naturalmente presentes no seu rúmenretículo, os quais utilizam a amônia como substrato para a síntese de suas próprias proteínas. Quando esses microrganismos passam do rúmen para o abomaso e duodeno com o bolo alimentar, são então digeridos pelo ruminante, que assim pode se beneficiar da proteína microbiana, de alta qualidade. Esse mecanismo ocorre inclusive em ruminantes que não recebem uréia exógena na dieta, pois uma pequena quantidade de uréia na saliva desses animais é 
CÂMARA, L.R.A. et al. Zeolita na dieta de bovinos de corte. PUBVET, Londrina, V. 5, N. 26, Ed. 173, Art. 1168, 2011.

proveniente da degradação normal das proteínas presentes no seu organismo. Através da ruminação, a saliva leva essa uréia do fígado para o rúmen-retículo, favorecendo a proliferação constante dos microrganismos. Portanto, ao adicionar uréia na ração dos seus animais, o pecuarista apenas está "potencializando" um mecanismo metabólico natural.

De acordo com Mumpton \& Fishman (1977), o uso de Zeolita na alimentação de ovinos reduziria os efeitos tóxicos do alto conteúdo de amônia no líquido ruminal. Os íons de amônia formados pela decomposição enzimática da uréia no rúmen seriam imediatamente trocados nas estruturas cristalinas da zeolita, onde permaneceriam por várias horas até que fossem liberados pela ação regeneradora do íon sódio provindo da saliva. Desse modo, a liberação gradual do íon amônio no rúmen permite aos microrganismos uma síntese contínua de proteína microbiana para uma melhor absorção no trato gastrintestinal do animal. Porém a exata função das zeolitas como aditivo na alimentação animal ainda não está bem definida.

A seletividade da clinoptilolita por amônia, segundo os autores acima, sugere que em ruminantes ela atua como um reservatório de nitrogênio no sistema digestivo dos animais, resultando numa liberação mais lenta e utilização mais eficiente dos íons de amônia produzidos pela degradação da proteína ingerida. A diminuição da velocidade de passagem pelo trato digestivo também pode ocorrer.

A liberação gradual da amônia permite aos microrganismos do rúmen a síntese contínua de proteína celular (Cass et al., 1994) e o produto resultante da uréia com zeolita pode trazer efeitos positivos na utilização desse suplemento nitrogenado para ruminantes.

McCollum \& Galyean (1983) estudaram o efeito da clinoptilolita sobre a fermentação ruminal e a digestão, em novilhos de corte alimentados com altos níveis de concentrado; os pesquisadores concluíram que o produto pode alterar a digestibilidade e a fermentação ruminal, quando incluído na dieta em níveis maiores que $1,25 \%$ da matéria seca. No entanto, Parré et al. (1997) incluíram a zeolita ao nível de $3 \%$, em dietas peletizadas para ovinos, e não observaram 
CÂMARA, L.R.A. et al. Zeolita na dieta de bovinos de corte. PUBVET, Londrina, V. 5, N. 26, Ed. 173, Art. 1168, 2011.

alterações nos coeficientes de digestibilidade aparente da matéria seca (MS), proteína bruta (PB), fibra em detergente neutro (FDN) e da energia bruta (EB); mas a inclusão do produto proporcionou uma melhor retenção de $\mathrm{N}$ pelos animais, em função da menor excreção de compostos nitrogenados pela urina.

No Brasil são poucas as pesquisas envolvendo a utilização da zeolita na dieta de bovinos, o comportamento da zeolita no trato digestivo dos animais ruminantes, sua digestibilidade, sua influência nos parâmetros fisiológicos, bem como a dinâmica exercida nos compartimentos rúmen-retículo com a utilização de níveis de clinoptilolita como aditivo na alimentação de bovinos de corte.

\subsection{Histórico da zeolita}

Com a descoberta da stilbita, as zeolitas foram reconhecidas pela primeira vez em 1756, pelo mineralogista sueco Baron Axel Frederick Consted. O termo zeolita (zéo e líthos) vem do grego e significa pedra que ferve. São aluminosilicatos de metais alcalinos ou alcalinos terrosos, predominantemente sódio e cálcio (Clarke, 1980). Em 1845, Way Breck descobriu que determinados tipos de solos tinham a propriedade de reter sais de amônia, e constatou que os silicatos hidratados de alumínio no solo eram os responsáveis pela troca iônica. Em 1925, Weigel \& Steinholf foram os primeiros a constatar que a zeolita chabazita absorvia seletivamente moléculas orgânicas menores e rejeitava as maiores. Em 1932, McBain denominou esse fenômeno de peneiramento molecular, e já nas décadas de 40 e 50, as pesquisas tomaram um impulso muito grande sobre as propriedades das zeolitas. A partir de então, ficou claro o potencial de utilização das zeolitas em processos industriais (Clifton, 1897).

Em 1862, a criação da primeira zeolita sintética foi relatada por St. Clair Deville, que produziu a zeolita levynita através do aquecimento em tubo de vidro, a $170^{\circ} \mathrm{C}$, de uma solução aquosa de silicato de potássio e aluminato de sódio. É creditado a Barrer (1951) a primeira síntese da zeolita analcima, caracterizada através de difração de raios- $X$, com reprodutibilidade de 
CÂMARA, L.R.A. et al. Zeolita na dieta de bovinos de corte. PUBVET, Londrina, V. 5, N. 26, Ed. 173, Art. 1168, 2011.

resultados, o que não havia sido até então obtido, devido à falta de técnicas adequadas. Em 1980 já haviam sido identificadas 40 zeolitas naturais. No final da década de 80 , já se conheciam mais de 10.000 patentes relacionadas com as zeolitas sintéticas (Gianneto, 1989).

Atualmente existem estudos que direcionam o uso da Zeolita na alimentação para melhorar a utilização dos nutrientes disponíveis aos animais.

No presente trabalho foi elaborada uma revisão sobre as zeolitas, envolvendo sua estrutura, classificação, propriedades, aplicações gerais e utilização na alimentação animal.

\subsection{Estrutura e classificação}

As zeolitas englobam um grande número de minerais naturais e sintéticos que apresentam características comuns. São aluminosilicatos hidratados de metais alcalinos ou alcalinos terrosos (principalmente sódio, potássio, magnésio e cálcio), estruturados em redes cristalinas tridimensionais, compostas de tetraedros do tipo $\mathrm{TO}_{4}(\mathrm{~T}=\mathrm{Si}, \mathrm{Al}, \mathrm{B}, \mathrm{Ge}, \mathrm{Fe}, \mathrm{P}$, Co...) unidos nos vértices através de átomos de oxigênio. Na Tabela 1 estão apresentadas as fórmulas naturais das zeolitas mais comuns.

Nas zeolitas mais comuns, na fórmula $\mathrm{TO}_{4}$, o T representa o Si ou o Al. A fórmula química por célula unitária é:

$\mathrm{Mx} / \mathrm{n}[(\mathrm{AlO} 2) \times(\mathrm{SiO} 2) \mathrm{y}] \cdot \mathrm{m} \mathrm{H} 2 \mathrm{O}$

Onde:

$M=$ cátion de valência $n$

$\mathrm{m}=$ número de moléculas de água

$\mathrm{x}+\mathrm{y}=$ número de tetraedros por célula unitária

A estrutura das zeolitas apresenta canais e cavidades interconectadas de dimensões moleculares, nas quais se encontram os íons de compensação, moléculas de água, ou outros adsorvatos e sais. 
CÂMARA, L.R.A. et al. Zeolita na dieta de bovinos de corte. PUBVET, Londrina, V. 5, N. 26, Ed. 173, Art. 1168, 2011.

Quadro1: Principais zeolitas naturais

\begin{tabular}{|c|c|}
\hline Zeolitas & Fórmula Química \\
\hline laumontita & $\mathrm{CaAl}_{2} \mathrm{Si}_{4} \mathrm{O}_{12} \cdot 4 \mathrm{H}_{2} \mathrm{O}$ \\
\hline Clinoptilolita & $(\mathrm{Na}, \mathrm{K}, \mathrm{Ca})_{2-3} \mathrm{Al}_{3}\left(\mathrm{Al}, \mathrm{Si}_{2} \mathrm{Si}_{13} \mathrm{O}_{36} \cdot{ }_{12} \mathrm{H}_{2} \mathrm{O}\right.$ \\
\hline stilbita & $\mathrm{NaCa}{ }_{2} \mathrm{Al}_{5} \mathrm{Si}_{13} \mathrm{O}_{36} \cdot 14 \mathrm{H}_{2} \mathrm{O}$ \\
\hline phillipsita & $(\mathrm{K}, \mathrm{Na}, \mathrm{Ca})_{1-2}(\mathrm{Si}, \mathrm{Al})_{8 \cdot} \mathrm{O}_{16} \cdot 6 \mathrm{H}_{2} \mathrm{O}$ \\
\hline erionita & $\left(\mathrm{K}_{2}, \mathrm{Ca}, \mathrm{Na}_{2}\right)_{2} \mathrm{Al}_{4} \mathrm{Si}_{14} \mathrm{O}_{36} .15 \mathrm{H}_{2} \mathrm{O}$ \\
\hline offretita & $\left(\mathrm{K}_{2}, \mathrm{Ca}\right)_{5} \mathrm{Al}_{10} \mathrm{Si}_{16} \mathrm{O}_{72} .3 \mathrm{OH}_{2} \mathrm{O}$ \\
\hline faujazita & $\left(\mathrm{Na}_{2} \mathrm{Ca}\right) \mathrm{Al}_{2} \mathrm{Si}_{4} \mathrm{O}_{12} .8 \mathrm{H}_{2} \mathrm{O}$ \\
\hline chabasita & $\mathrm{CaAl}_{2} \mathrm{Si}_{4} \mathrm{O}_{12} \cdot 6 \mathrm{H}_{2} \mathrm{O}$ \\
\hline natrolita & $\mathrm{Na}_{2} \mathrm{Al}_{2} \mathrm{Si}_{3} \mathrm{O}_{10} \cdot 2 \mathrm{H}_{2} \mathrm{O}$ \\
\hline tromsonita & $\mathrm{NaCa}_{2} \mathrm{Al}_{5} \mathrm{Si}_{5} \mathrm{O}_{20} \cdot 6 \mathrm{H}_{2} \mathrm{O}$ \\
\hline mordenita & $\left(\mathrm{Ca}, \mathrm{Na}_{2}, \mathrm{~K}_{2}\right) \mathrm{Al}_{2} \mathrm{Si}_{10} \mathrm{O}_{24 .} \cdot \mathrm{H}_{2} \mathrm{O}$ \\
\hline epistilbita & $\mathrm{CaAl}_{2} \mathrm{Si}_{6} \mathrm{O}_{16 .} 5 \mathrm{H}_{2} \mathrm{O}$ \\
\hline analcima & $\mathrm{Na}, \mathrm{AlSi}_{2} \mathrm{O}_{6} \cdot \mathrm{H} 2 \mathrm{O}$ \\
\hline heulandita & $(\mathrm{Na}, \mathrm{Ca})_{2-3} \mathrm{Al}_{3}(\mathrm{Al}, \mathrm{Si})_{2} \mathrm{Si}_{13} \mathrm{O}_{36} \cdot 12 \mathrm{H}_{2} \mathrm{O}$ \\
\hline
\end{tabular}

Adaptado: Fleischer \& Mandarino, 1991.

Esse tipo de estrutura microporosa confere às zeolitas uma superfície interna muito grande (Figura 1), quando comparada à sua superfície externa. A estrutura da zeolita permite a transferência de matéria entre os espaços intracristalinos, no entanto, essa transferência é limitada pelo diâmetro dos poros das zeolitas. Dessa forma, só podem ingressar ou sair do espaço intracristalino aquelas moléculas cujas dimensões são inferiores a certo valor crítico, que varia de uma zeolita para outra (Gianneto,1989).
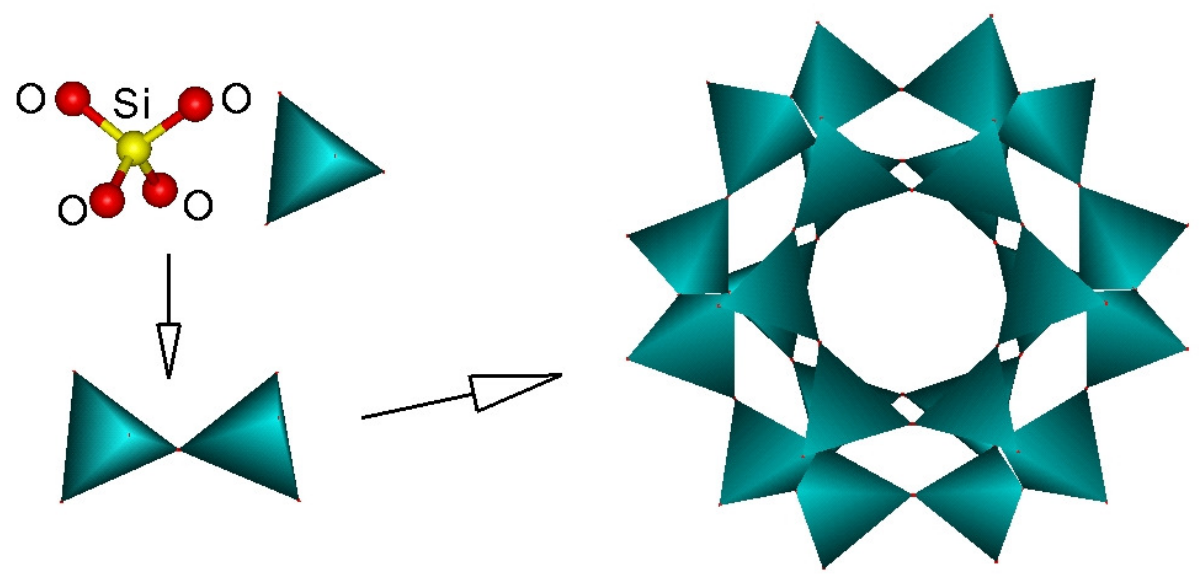

Figura 1. Estrutura básica da zeolita. 
CÂMARA, L.R.A. et al. Zeolita na dieta de bovinos de corte. PUBVET, Londrina, V. 5, N. 26, Ed. 173, Art. 1168, 2011.

\subsection{Propriedades das zeolitas}

A estrutura das zeolitas confere às mesmas propriedades de grande importância para os processos industriais (Clifton, 1897 e Jiexiang, 1993), tais como:

a) alto grau de hidratação;

b) baixa densidade e grande volume de espaços vazios quando desidratada;

c) estabilidade da estrutura cristalina, quando desidratada;

d) propriedades de troca catiônica;

e) canais uniformes nos cristais desidratados;

f) condutividade elétrica;

g) adsorção de gases e vapores e

h) propriedades catalíticas.

A alta eficiência de adsorção das zeolitas está relacionada com a grande superfície interna, devido à sua estrutura cristalina ser caracterizada por cavidades espaçosas. A mordenita tem uma superfície interna de $400 \mathrm{~m}^{2} / \mathrm{g}$, e a da clinoptilolita é de $300 \mathrm{~m}^{2} / \mathrm{g}$. Para o caso da mordenita, a quantidade de $\mathrm{SO}_{2}$ adsorvido é $47-120 \mathrm{ml} / \mathrm{g}$.

A grande capacidade de troca catiônica das zeolitas deve-se ao desequilíbrio de cargas que atrairão o cátion mais próximo, de maneira a manter a neutralidade.

A propriedade de troca catiônica das zeolitas é uma função da relação Si e Al. A capacidade é expressa em número de cátions por unidade de massa ou volume, disponível para troca. A propriedade catalítica está relacionada principalmente com as superfícies ativas da estrutura das zeolitas, com o sistema interno de passagens e vazios, o tamanho das cavidades internas e a propriedade de troca catiônica. Segundo Pergher (2005), a capacidade de adsorção das zeolitas é resultante da sua alta área superficial e de sua carga líquida negativa nos canais de sua estrutura que atrai cátions, tais como os metais pesados, $\mathrm{NH}_{4}{ }^{+}, \mathrm{K}^{+}, \mathrm{Ca}^{2+}, \mathrm{Na}^{+}$e $\mathrm{Mg}^{2+}$. 
CÂMARA, L.R.A. et al. Zeolita na dieta de bovinos de corte. PUBVET, Londrina, V. 5, N. 26, Ed. 173, Art. 1168, 2011.

\subsection{Usos das Zeolitas Naturais}

Desde a época dos romanos, as cinzas vulcânicas desvitrificadas e rochas tufosas alteradas têm sido usadas na fabricação de cimento pozolânico e concreto e, no decorrer da história, em diversas partes do mundo, como agregados leves na construção civil. No entanto, só nos últimos 40 anos, as zeolitas passaram a ser identificadas na maioria desses materiais.

A partir da década de 50, ocorreram as descobertas de centenas de depósitos sedimentares de zeolita, motivadas pelos baixos custos de lavra desses depósitos e pela potencialidade de uso industrial da zeolita natural, a partir das propriedades físicas e químicas da sua estrutura cristalina (Mumpton, 1973).

As principais utilizações da Zeolita são (Luz, 1994; Rezende, 1997; Mumpton, 1999): agente solubilizador de apatitas para a adubação fosfática de culturas; cama para animais domésticos; condicionador de solos agrícolas; construção civil; descontaminação de metais pesados ( $\mathrm{Cu}, \mathrm{Cr}, \mathrm{Pb}, \mathrm{Zn}$, etc.) e de isótopos radioativos $\left(\mathrm{Sr}^{90}, \mathrm{Cs}^{137}\right.$, etc.); descontaminação de micotoxinas (aflatoxinas) em alimentos; filtro para indústria; formulação de herbicidas, inseticidas e fungicidas;preservação de frutas; preservação de grãos e de sementes; produção de adubos organominerais; produção de compostos por processos aeróbios ou anaeróbios; produção de fertilizantes de liberação lenta; substrato artificial para cultivo de plantas; suplemento na alimentação animal; tratamento de água para consumo humano e animal; tratamento de águas contaminadas; tratamento de esterco e de resíduos orgânicos e tratamento médico.

\subsection{Utilização da Zeolita na Alimentação Animal}

As características físicas e químicas das zeolitas naturais conferem a esses minerais, várias possibilidades de uso na criação animal, tanto no tratamento de resíduos como na própria alimentação. De acordo com Mumpton (1999), no tratamento de resíduos animais com zeolitas, destacam-se a redução de odores, de poluição, a possibilidade de ambientes mais saudáveis 
CÂMARA, L.R.A. et al. Zeolita na dieta de bovinos de corte. PUBVET, Londrina, V. 5, N. 26, Ed. 173, Art. 1168, 2011.

para os animais, o controle da viscosidade, a retenção de nutrientes do esterco e a purificação do metano produzido na decomposição anaeróbia de excrementos.

Existem vários relatos na literatura que mostram vantagens de utilização desse mineral nas dietas de aves, suínos e ruminantes. O uso de zeolitas na dieta $(5 \%)$ possibilita o aumento da eficiência da conversão alimentar (entre $20 \%$ e $30 \%$ ) e a manutenção dos mesmos ganhos de peso resultantes de dietas sem o mineral, porém com menor quantidade de alimento e de água (Mumpton, 1999).

Uma extensa revisão sobre o papel de zeólitas naturais e sintéticas como aditivos nutricionais na prevenção e/ou no tratamento de doenças de animais foi apresentada por Papaioannou et al. (2005). No caso de vacas leiteiras, o uso da zeolita possibilitaria prevenir doenças metabólicas, como hipocalcemia. Além disso, a zeolita também poderia evitar distúrbios gastrintestinais, incluindo parasitoses intestinais. Com relação ao alimento, a zeolita teria um potencial absorvente de micotoxinas, oferecendo ao animal um alimento descotaminado ou com níveis aceitáveis de aflatoxinas.

\subsection{Dieta de Ruminantes}

Na nutrição de ruminantes, uma das fontes de amônia pode ser a uréia, cuja alta solubilidade no rúmen, pode limitar o seu uso. Os microrganismos do rúmen têm a capacidade de transformar o nitrogênio da dieta em proteína de boa qualidade. O nitrogênio tanto pode vir de proteínas verdadeiras (ex.: farelo de soja, farelo de algodão, forragens, outros) quanto de alguns compostos inorgânicos (compostos nitrogenados não-proteicos), como uréia, biureto e ácido úrico.

A capacidade das bactérias para utilizarem o nitrogênio não-proteico (NNP) vai depender, primariamente, da quantidade e do nível de degradação da energia fornecida ao animal (carboidratos) e da capacidade de crescimento da população de microrganismos, mas existe um limite para o crescimento microbiano, o qual, teoricamente, depende da ingestão de energia. Quando a 
CÂMARA, L.R.A. et al. Zeolita na dieta de bovinos de corte. PUBVET, Londrina, V. 5, N. 26, Ed. 173, Art. 1168, 2011.

uréia alcança o rúmen, ela é rapidamente convertida em amônia e $\mathrm{CO}_{2}$ pela enzima urease, produzida pelas bactérias. A amônia presente no rúmen, resultante da uréia ou da degradação da proteína da dieta, é utilizada pelos microrganismos para a síntese de sua própria proteína. Para que isso ocorra, é essencial a presença de uma fonte de energia (celulose das forragens ou amido do milho, por exemplo). A proteína assim formada é chamada de proteína microbiana, como pode ser observado na Figura 2. À medida que a digestão ruminal progride, o alimento ingerido pelo animal, juntamente com as bactérias e seus produtos, continuam a avançar pelo trato digestivo. Quando a digesta alcança o abomaso, que possui grande acidez e é considerado o estômago verdadeiro dos ruminantes, as bactérias são destruídas e seu conteúdo é liberado. No abomaso e no intestino delgado, as frações alimentares são digeridas. A digestão da proteína bacteriana nada mais é do que sua quebra em aminoácidos, os quais serão absorvidos no intestino e novamente transformados em proteínas pelo próprio animal. Existe ainda a uréia endógena (produzida no metabolismo animal), que é sintetizada no fígado do próprio animal. Nesse processo, a amônia proveniente da degradação da proteína ou da uréia ingerida é absorvida pela parede do rúmen e chega ao fígado pela veia porta. No fígado, essa amônia é convertida em uréia. Parte dessa uréia volta ao rúmen, parte vai para a saliva e parte é excretada pela urina. 
CÂMARA, L.R.A. et al. Zeolita na dieta de bovinos de corte. PUBVET, Londrina, V. 5, N. 26, Ed. 173, Art. 1168, 2011.

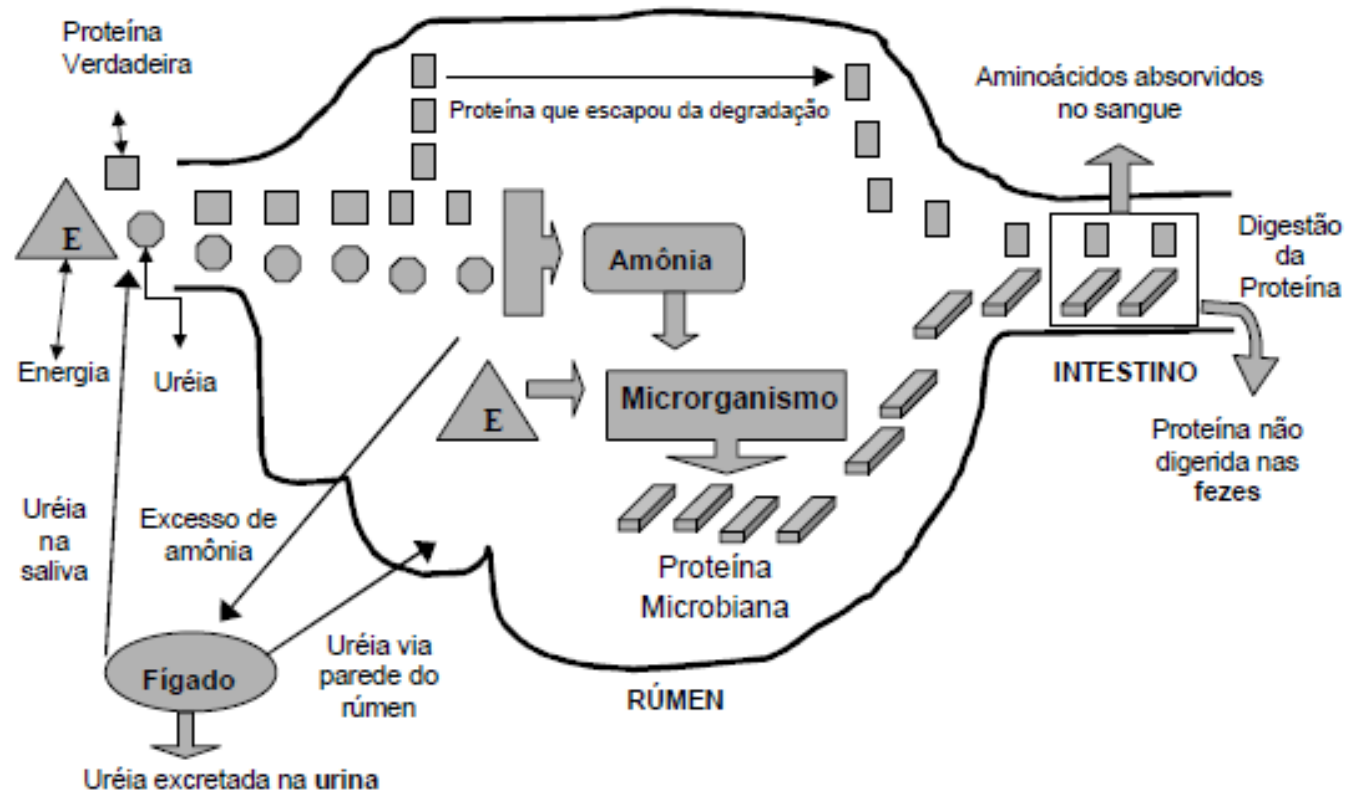

Figura 2: Esquema simplificado do metabolismo de proteínas em ruminantes.

Em alguns casos, a uréia transforma-se em amônia numa velocidade maior que a formação de ácidos graxos voláteis, necessários para a síntese de proteína microbiana. Em conseqüência, grande quantidade de nitrogênio amoniacal é absorvido pela parede do rúmen, sobrecarregando o fígado e aumentando a concentração de amônia no sangue, o que caracteriza um quadro de intoxicação, que pode ser agravado quando o consumo de uréia se dá em curto espaço de tempo (Owens\& Zinn, 1988).

Uma alternativa para evitar esse problema é o emprego de complexos de liberação lenta de uréia (Owens \& Zinn, 1988), de modo a melhorar a velocidade de fornecimento de amônia no rúmen e aumentar a síntese de proteína microbiana, consumo de matéria seca e a digestibilidade da fibra, e assim proporcionar maior consumo de energia pelo animal, além de reduzir problemas com toxidez (Russell et al., 1992; Tedeschi et al., 2000).

A liberação gradual da amônia permite aos microrganismos do rúmen a síntese contínua de proteína celular (Cass et al., 1994), pois eles possuem intensa atividade proteolítica. As proteínas são digeridas em peptídeos (moléculas menores), aminoácidos livres e amônia e a extensão dessa 
CÂMARA, L.R.A. et al. Zeolita na dieta de bovinos de corte. PUBVET, Londrina, V. 5, N. 26, Ed. 173, Art. 1168, 2011.

digestão difere grandemente de acordo com a solubilidade da proteína presente na dieta.

O produto resultante da uréia com zeolita pode trazer efeitos positivos na utilização desse suplemento nitrogenado para ruminantes. White \& Ohlrogge (1974) foram os primeiros a descrever o efeito da retenção dos íons amônio, formados pela decomposição enzimática de compostos nitrogenados nãoprotéicos, na estrutura de zeolitas.

A atividade de desaminação pelas bactérias do rúmen resulta na produção de amônia, dióxido de carbono e ácidos graxos voláteis de cadeia curta e não varia muito com o conteúdo de proteína da dieta. As bactérias utilizam a amônia disponível no conteúdo ruminal como principal fonte de nitrogênio para a síntese de proteína microbiana. Algumas espécies de bactérias utilizam diretamente os peptídeos e aminoácidos formados no rúmen. Mas, amônia é o principal constituinte de nitrogênio solúvel presente no fluido ruminal. Sua concentração depende (1) da quantidade e solubilidade da proteína da dieta, (2) da quantidade de uréia que é reciclada no rúmen através da saliva (3) da difusão da uréia pela parede do rúmen e (4) da taxa de absorção da amônia do rúmen. A uréia é uma fonte de nitrogênio não protéico rapidamente hidrolisada pelas bactérias do rúmen em amônia e dióxido de carbono em uma velocidade quatro vezes superior a sua capacidade de incorporação à proteína microbiana pelos microorganismos, ficando dependente de diversos fatores para sua utilização, quando a concentração de amônia exceder 5 a $8 \mathrm{mg} / 100 \mathrm{ml}$ de líquido ruminal, como disponibilidade de carboidratos, minerais e até mesmo um aditivo, como é o caso da zeolita, que possui afinidade pela amônia, fazendo com que seja liberada gradativamente no ambiente ruminal, aumentando sua utilização pelos microrganismos ruminais.

Os resultados indicaram tanto em experimentos in vitro como in vivo, que mais de $15 \%$ do $\mathrm{NH}_{4}$ do rúmen poderia ser retido. Hemken et al. (1984) mostraram que a suplementação de $6 \%$ de clinoptilolita na ração de vacas 
CÂMARA, L.R.A. et al. Zeolita na dieta de bovinos de corte. PUBVET, Londrina, V. 5, N. 26, Ed. 173, Art. 1168, 2011.

leiteiras que continha uréia reduziu significativamente a concentração ruminal de $\mathrm{NH}_{3}$.

No Brasil, Parré et al. (1997) testaram a inclusão da zeolita em rações peletizadas com uréia e farelo de algodão para ovinos. Os resultados obtidos indicaram que a zeolita e uréia utilizadas na proporção de 3,3:1 não alterou os coeficientes de digestibilidade aparente da matéria seca, proteína bruta, fibra insolúvel em detergente neutro e energia bruta. Esses autores concluíram que o uso da zeolita na proporção de $3 \%$ da ração que continha farelo de algodão e uréia melhorou a retenção de nitrogênio pelos animais. Esses resultados foram semelhantes aos obtidos por Galindo et al. (1990).

Coutinho Filho et al. (2002) avaliaram a inclusão de zeolita na dieta de bezerros machos da raça Santa Gertrudes. A inclusão de $2,4 \%$ de zeolita no concentrado ( $1,1 \%$ na matéria seca da ração) não afetou significativamente as variáveis estudadas, que foram, respectivamente, dos tratamentos sem e com 2,4\% de zeolita: ganho de peso vivo diário de 1,35 e 1,41 kg; consumo diário de matéria seca em relação ao peso vivo de 2,53\% e 2,59\%; conversão alimentar de 6,03 e 5,93 kg de matéria seca por $\mathrm{kg}$ de ganho de peso; e pH das fezes de 5,36 e 5,51. Os dados médios da avaliação de carcaça foram: rendimento quente, $54,22 \%$ e 55,56\%; área de olho de lombo, 26,72 e 26,92 $\mathrm{cm}^{2}$ por $100 \mathrm{~kg}$, e gordura renal pélvica, 2,4\% e 2,6\%, respectivamente.

Câmara et al.(2010) trabalhou com bovinos fistulados adicionando níveis de zeolita $(0 \%, 0,75 \%, 1,5 \%, 2,25 \%$ e $3,0 \%)$ na MS do concentrado e concluiu que a adição de zeolita na ração não melhora a utilização da ureia em dietas de bovinos de corte, uma vez que não altera o consumo e a digestibilidade de quase todos os nutrientes avaliados, bem como, não afeta os parâmetros ruminais.

Dietas ricas em zeolita também podem exercer efeito benéfico sobre a prevenção de certas doenças metabólicas em gado de leite, como a hipocalcemia ou febre do leite (Papaioannou et al., 2005). O objetivo do tratamento é reduzir a biodisponibilidade de $\mathrm{Ca}^{2+}$ da dieta mediante fornecimento de zeolita, com base na evidência de que um dos melhores meios 
CÂMARA, L.R.A. et al. Zeolita na dieta de bovinos de corte. PUBVET, Londrina, V. 5, N. 26, Ed. 173, Art. 1168, 2011.

de prevenção da doença é a alimentação das vacas com baixa quantidade de $\mathrm{Ca}^{2+}$ durante o período seco. Katsoulos et al. (2005) mostraram esse efeito fornecendo clinoptilolita para vacas de leite. A incidência da febre do leite foi significativamente menor naquelas que receberam dieta com 2,5\% de zeolita (6\%) durante o último mês do período seco até o início da lactação, comparada com animais do grupo controle (39\%). Ilić et al. (2007) também trabalharam com adição de zeolita para bovinos para prevenção de doenças e encontraram resultados satisfatórios.

\section{Referências bibliográficas}

BERGEN, W.G.; BATES, D.B. Ionophores: their effect on production efficiency and mode of action. Journal of Animal Science, v.58, n.6, p.1465-1483, 1984.

CÂMARA, L.R.A. Zeolita em dietas de bovinos de corte. Viçosa, MG: UFV, 2010, 36p. Dissertação (Mestrado em Zootecnia) - Universidade Federal de Viçosa, 2010.

CASS, J. L.; RICHARDSON, C. R.; SMITH, K .J. Evaluation of slow ammonia release from urea/calcium compounds. Journal of Animal Science, Champaign, v. 72, p. 243, 1994.

CASTRO, M., E. LON-WO, R. GARCÍA-LOPEZ, J. GALINDEZ Y M. U. ZALDIVAR. Las zeolitas naturales cubanas en la produccion animal. Seminário Científico Internacional, XXV Aniversário, Instituto de Ciência Animal, 24 a 26 de outubro de 1990. Habana, Cuba. 1990.

CLARKE, C. Zeolites: Take off for the Tuff Guys; Industrial Minerals, p. 21-32. Feb. 1980.

CLIFTON, R. A. Natural and synthetic zeolites, Washington: Bureau of Mines, 1987. 21p. (Information Circular; 9140).

COUTINHO FILHO, J. L. V.; HENRIQUE, W.; PERES, R. M.; JUSTO, C. L.; SIQUEIRA, P. A.; COSER, P. S. Efeito da zeólita na engorda de bovinos em confinamento. Archivo Latinoamericano de Produção Animal, v. 10, n. 2, p. 93-96, 2002.

FLEISCHER, M. E MANDARINO, J.A. Glossary of mineral species, The Mineralogical Record IncTucson-USA, 1991

GALINDO, J.; ELIAS, A.; PIEDRA, R. The effect of some zeolite components on the rumen microbial activity of silage diets. Cuban Journal of Agricultural Science, La Habana, v. 24, p. 187-194. 1990.

GIANNETO, P. Zeolitas: características, propriedades y aplicaciones industriales. In: Síntese de Zeolitas. [s.I.]; Editorial Inovación Tecnológica, 1989. cap. 2 e 4.

HEMKEN, R. W.; HARMON, R. J.; MANN, L. M. Effect of clinoptilolite on lactating dairy cows fed a diet containing urea as a source of protein. In: POND, W. G.;1984. 
ILIĆ, Z; PEŠEV, S; MILENKOVIĆ, M; MILOŠEVIĆ, B. Impact on the zeolita usage in diary cows nutrition to their health characteristics.Biotechnology in Animal Husbandry. v.23 (5-6), p $25-33,2007$.

JIEXIANG, G., SUREN, T. The application of natural zeolite in China, In: PROCEeDING OF THE INTERNATIONAL CONGRESS ON APPLIED MINERALOGY; ICAM'93, Fremantle, Wester Australia, May, 31/June, 2, 1993.

KATSOULOS, P. D.; ROUBIES, N.; PANOUSIS, N.; ARSENOS, G.; CHRISTAKI, E.; KARATZIAS, $\mathrm{H}$. Effects of long-term dietary supplementation with clinoptilolite on incidence of parturient paresis and serum concentrations of total calcium, phosphate, magnesium, potassium, and sodium in dairy cows. American Journal of Veterinary Research, v. 66, n. 12, p. 20812085, 2005.

LUZ, A. B. Zeólitas: propriedades e usos industriais. Rio de Janeiro: CETEM-CNPq, 1994. 37 p. (CETEM. Série Tecnologia Mineral, 68).

MCCOLLUM, F. T. AND M. L. GALYEAN. 1983. Effects of clinoptilolite on rumen fermentation digestion and feedlot performance in beef steers fed high concentrate diets. Journal of Animal Science. 56: 517-524.

MUMPTON, F. A. AND P. H. FISHMAN. The application of natural zeolites in animal science and aquaculture. Journal of Animal Science. 45: 1188-1203, 1977.

MUMPTON, F. A. La roca magica: Uses of natural previous zeolites in agriculture and industry. Proceedings of National Academy of Sciences of the United States of America, v. 96, n. 7, p. 3463- 3470, 1999

MUMPTON, F. A. (Ed.). Zeoagriculture. Use of natural zeolites in agriculture and aquaculture. Boulder, CO: Westview Press Inc., 1984. p. 171-174.

MUMPTON, F.A. Worldwide deposits and utilization of natural zeolites, Industrial Minerals, p. 30/45, Oct. 1973.

OWENS, F. N.; ZINN, R. Protein metabolism of ruminant animal. In: $\mathrm{CHURCH,} \mathrm{D.} \mathrm{C.} \mathrm{(Ed.).} \mathrm{The}$ ruminant animal: digestive physiology and nutrition. Englewood Cliffs: Simon \& Schuster, 1988. p. 227-249.

PAPAIOANNOU, D.; KATSOULOS, P. D.; PANOUSIS, N.; KARATZIAS, H. The role of natural and synthetic zeolites as feed additives on the prevention and/or the treatment of certain farm animal diseases: A review. Microporous and Mesoporous Materials, v. 84, p. 161-170, 2005.

PARRÉ, C.; VIEIRA, P. F.; SILVEIRA, A. C.; ARRIGONI, M. B.; BeRTO, D. A.; CURI, P. R. Utilização de uréia e zeólita na alimentação de ovinos. Digestibilidade e balanço de nitrogênio. In: Reunião da sociedade brasileira de zootecnia, 34., 1997,Juiz de Fora, MG. Anais... Juiz de Fora: Sociedade Brasileira de Zootecnia, 1997. 3 p. 1 CD-ROM.

PERGHER, SIBELE B. C., OLIVEIRA, Luiz C. A., SMANIOTTO, Alessandra et al. Materiais magnéticos baseados em diferentes zeólitas para remoção de metais em água. Química Nova, set./out. 2005, vol.28, no.5, p.751-755. ISSN 0100-4042. 
PERGHeR, Sibele B. C., CAOVILlA, Marcela, DETONI, Chaline et al. Remoção de Cu+2 de soluções aquosas em zeólita NaX: efeito da granulometria. Química Nova, maio/jun. 2005, vol.28, n.3, p.397-401. ISSN 0100-4042.

QUARLES, C. L. Zeolites: a new ingredient may cut calories needed to produce poultry, red meat. Feedstuffs, p. 35. 1985

REZENDE, N. G. A. M. Argilas nobres e zeólitas na bacia do Paraíba; relatório final de projeto. Belém: Companhia de Pesquisa de Recursos Minerais, 1997. 33 p.

RUSSELL, J. B.; O'CONNOR, J. D.; FOX, D. G.; SOEST, P.J. van.; SNIFFEN, C. J. A net carbohydrate and protein system for evaluating cattle diets. I. Ruminal fermentation. Journal of Animal Science, v.70, p. 3551-3561, 1992.

TEDESCHI, L. O.; FOX, D. G.; RUSSELL, J. B. Accounting for the effects of a ruminal nitrogen deficiency within the structure of the Cornell net carbohydrate and protein system. Journal of Animal Science, v. 78, p. 1648-1658, 2000.

WHITE, J. L.; OHLROGGE, A. J. Ion exchange materials to increase consumption of nonprotein nitrogen in ruminants. Canadian patent 939186, 2 January 1974. 